\title{
A IMPORTÂNCIA DA PARTICIPAÇÃO PÚBLICA NOS PROCESSOS ESTRUTURAIS: CONTRIBUIÇÕES DA TEORIA NORMATIVA DE SUSAN STURM
}

\section{THE IMPORTANCE OF PUBLIC PARTICIPATION IN STRUCTURAL LITIGATION: CONTRIBUTIONS FROM SUSAN STURM'S NORMATIVE THEORY}

\author{
FELIPE BRAGA AlbUQUERQUE ${ }^{1}$ \\ MATHEUS CASIMIRO GOMES SERAFIM ${ }^{2}$
}

\begin{abstract}
RESUMO: Analisa-se a importância da participação pública nos processos estruturais, e como a teoria normativa de Susan Sturm pode contribuir com o aperfeiçoamento de sentenças estruturais dialógicas. Quando se fala sobre demandas estruturais, está sempre presente o dilema da justiciabilidade dos direitos socioeconômicos, em face do qual o Judiciário só possuiria duas alternativas: deferência ou ativismo solipsista. $O$ trabalho defende que as sentenças dialógicas são uma solução para o referido dilema, visto que, com a utilização desse modelo decisório, os órgãos judiciais não precisam formular as políticas públicas a serem executadas no caso concreto. Para a realização da pesquisa, utilizou-se o estudo bibliográfico das principais obras sobre litígios estruturais, em especial a obra de Susan Sturm. A autora aponta cinco importantes diretrizes para o desenvolvimento de remédios estruturais dialógicos e eficientes: participação, respeito à separação de poderes, imparcialidade, fundamentação adequada das decisões e remediação. Concluiu-se que, com base nos critérios apontados por Sturm, é possível desenvolver um remédio estrutural dialógico e eficiente.
\end{abstract}

Palavras-chave: Processos Estruturais; Sentenças Estruturais; Participação Pública.

\footnotetext{
${ }^{1}$ Professor Adjunto da Universidade Federal do Ceará (UFC), onde leciona na Graduação e na PósGraduação stricto sensu. Pós-doutorando em Saúde Coletiva pela UFC. Doutor em Direito Constitucional pela Universidade de Fortaleza (UNIFOR). E-mail: felipe_direito@hotmail.com.

2 Mestrando do Programa de Pós-Graduação em Direito da Universidade Federal do Ceará (PPGD/UFC), com área de concentração em Constituição, Sociedade e Pensamento Jurídico. Email: mcgserafim@gmail.com.
} 


\begin{abstract}
This paper analyzes the importance of public participation in structural litigation, and how Susan Sturm's normative theory can contribute to the improvement of dialogical structural interdicts. When talking about structural litigation, the dilemma of the justiciability of socio-economic rights is always present, in view of which the Judiciary would have only two alternatives: deference or solipsist activism. The paper argues that the dialogical interdicts are a solution to the referred dilemma, since, with the use of this decision model, the judicial organs do not need to formulate the public policies to be executed in the specific case. To carry out the research, we used the bibliographic study of the main works on structural litigation, in particular the work of Susan Sturm. The author points out five important guidelines for the development of dialogical and efficient structural remedies: participation, respect for the separation of powers, impartiality, adequate reasoning of decisions and remediation. It was concluded that, based on the criteria pointed out by Sturm, it is possible to develop a dialogical and efficient structural remedy.
\end{abstract}

Keywords: Structural Litigation; Structural Interdicts; Public Participation.

\title{
INTRODUÇÃO
}

O artigo analisa a importância da participação pública nos processos estruturais, e como a teoria normativa de Susan Sturm pode contribuir com o aperfeiçoamento de sentenças estruturais dialógicas e participativas.

Quando se trata de litígios estruturais, uma das questões mais controversas é qual o papel do Judiciário na efetivação dos direitos socioeconômicos. Por um lado, caso escolha a opção da deferência às escolhas do Poder Público, pode tornar normativamente vazio o rol de direitos sociais. Por outro, adotando uma postura ativista, pode usurpar competências próprias da Administração Pública, tornando o litígio estrutural ilegítimo e ineficiente.

O presente trabalho pretende apontar uma solução para esse dilema: a adoção de sentenças estruturais dialógicas e participativas. Com a utilização desse modelo decisório, o Judiciário não precisa formular as políticas públicas a serem executadas no caso concreto. Na verdade, a sua função seria a de retirar da inércia o Poder Público, conduzindo um diálogo entre os órgãos estatais e os segmentos social afetado pelas omissões políticas. Para construir uma sentença dialógica apta a produzir bons resultados, a teoria normativa de Susan Sturm oferece importantes contribuições, estabelecendo diretrizes que podem aperfeiçoar a atuação judicial nessa espécie de litígio.

Dessa forma, o artigo se divide em três partes principais. No primeiro tópico, estudam-se os autores mais relevantes para a compreensão de conceitos 
fundamentais à pesquisa, como processos estruturais, sentenças estruturais e omissões políticas. Analisa-se também como os processos estruturais têm se desenvolvido no Brasil, em especial no caso da ADPF no 347/DF. No segundo tópico, apresenta-se o ativismo judicial dialógico, bem como sua ligação com as sentenças estruturais participativas e com o experimentalismo democrático. Por fim, o último tópico apresenta o pensamento de Susan Sturm, e suas contribuições para a utilização de remédios estruturais participativos. Como metodologia de pesquisa, utiliza-se o estudo bibliográfico das principais referências sobre processos estruturais, com especial foco na obra de Susan Sturm, e também a análise da ADPF no 347/DF, em razão da sua relevância para o desenvolvimento dos processos estruturais no país.

\section{A RESPOSTA DO JUDICIÁRIO ÀS OMISSÕES POLÍTICAS: AS SENTENÇAS ESTRUTURAIS E A SUA UTILIZAÇÃO NO BRASIL}

O fim da Segunda Guerra Mundial é um divisor de águas para o constitucionalismo contemporâneo. As Constituições elaboradas no pós-guerra incluíram uma ampla diversidade de diretos fundamentais, tratando, inclusive, de matérias que até então não eram consideradas como tipicamente constitucionais (BEATTY, 2014, p. 16). Dentre as inovações apresentadas pelas declarações de direitos, é possível destacar a presença dos direitos sociais, econômicos e culturais (LANDAU, 2012, p. 193), retomando a tendência iniciada pela Constituição mexicana, de 1917, e pela Constituição de Weimar, de 1919.

Concomitantemente a esse processo, iniciou-se também o estudo da dimensão objetiva dos direitos fundamentais. Conforme explica Nascimento (2016, p. 68), a dimensão objetiva se destina à conformação da atuação estatal em seus mais diversos âmbitos, de tal forma que o Estado deve atuar constantemente em prol da efetivação desses direitos, ainda que não haja ações individuais exigindo alguma prestação do Poder Público. Assim, os direitos fundamentais não são mais vistos apenas como escudos que protegem o cidadão contra intervenções estatais, mas como diretrizes que devem nortear toda atuação do Estado.

A previsão de um extenso rol de direitos, entretanto, não foi suficiente para assegurar a sua concretização. $\mathrm{Na}$ verdade, essa positivação teve caráter predominantemente simbólico, e não instrumental. Diferenciando os dois conceitos, Neves (1996, p. 325) explica que toda Constituição possui uma dimensão simbólica, destinada a influenciar o imaginário social, consagrando valores relevantes para a sociedade, e também uma dimensão instrumental, a qual intenta conformar, efetivamente, a realidade política e social subjacente. O verdadeiro problema não é a existência dessa dupla dimensão, mas a subordinação da primeira em face a segunda.

Em consequência da falta de efetivação dos direitos fundamentais, surgem as chamadas omissões políticas, que estão no centro dos processos estruturais (FERRAZ, 2014, p. 121). Nesse caso, o termo omissão não se refere a um vácuo 
normativo. Afinal, é possível que exista ampla diversidade normativa tratando sobre determinado tema e, ainda assim, existir uma grave omissão política. Portanto, a omissão política pode ser compreendida como a falta de políticas públicas necessárias à proteção de direitos constitucionalmente assegurados, ocasionando-lhes profundas e reiteradas violações por parte do Poder Público (MARMELSTEIN, 2015a, p. 25).

Os processos estruturais são uma resposta às referidas omissões, e surgem quando grupos sociais afetados pela inércia estatal buscam a intervenção judicial para alcançar políticas públicas necessárias à proteção dos seus direitos. Assim, para compreender a teoria normativa de Sturm, é necessário, primeiramente, entender o que são as sentenças estruturais, os seus diferentes modelos, e como as decisões estruturais têm sido implementadas no Brasil.

\subsection{As sentenças estruturais como chaves de acesso para as políticas públicas}

Tendo em vista as omissões políticas, os segmentos populacionais por elas afetados acabam recorrendo ao Judiciário, com o intuito de obter uma solução para a inércia estatal. Surgem, assim, as demandas estruturais, processos complexos que envolvem múltiplos interesses e intentam modificar a estrutura de determinadas instituições, geralmente públicas. Questões típicas de litígios estruturais envolvem diversos valores da sociedade, da mesma forma que, não só há vários interesses concorrentes em jogo, mas também há a possibilidade de que as esferas jurídicas de terceiros, os quais não integram o conflito, sejam afetadas pela decisão judicial (ARENHART, 2017, p. 423-424).

Tratando do tema, Vitorelli (2015, p. 564) faz um paralelo entre o processo judicial tradicional e os processos estruturais. No modelo tradicional, opera o binômio direito-obrigação: caso seja comprovada a existência da violação de um direito, o Judiciário determina a sua reparação. A indenização dos segmentos populacionais afetados, no entanto, não soluciona a omissão política e, por consequência, não impede que as violações continuem ocorrendo. Dessa forma, os processos estruturais têm, como ponto de partida, a sistemática violação aos direitos fundamentais, mas o objetivo não é apenas reparar os danos já ocasionados, e sim promover uma readequação das políticas públicas necessárias à efetivação dos direitos violados ou reorganizar estruturalmente as instituições responsáveis por realizá-las (VITORELLI, 2015, p. 564). Sintetizando o conceito de litígios estruturais, o autor (2017, p. 372) explica:

Em resumo, litígios estruturais, para os efeitos do presente estudo, são aqueles que envolvem conflitos multipolares, de elevada complexidade, cujo objetivo é promover valores públicos pela via jurisdicional, mediante transformação de uma instituição pública ou privada. Há necessidade de reorganização de toda uma instituição, com a alteração de seus processos internos, de sua 
estrutura burocrática e da mentalidade de seus agentes, para que ela passe a cumprir sua função de acordo com o valor afirmado pela decisão.

Nesse contexto, o Judiciário, em todo o mundo, tem proferido sentenças estruturais que viabilizam a intervenção judicial no âmbito de atuação dos poderes políticos, no intuito de sanar, ainda que parcialmente, as omissões políticas do Estado. Esses provimentos jurisdicionais não intentam apenas apontar que detém a razão no caso concreto, afirmando os direitos que devem ser protegidos (OSNA, 2017, p. 590). Quando o Judiciário recorre às sentenças estruturais, ele vai além: objetiva intervir no funcionamento das instituições envolvidas nos litígios, para que novas políticas públicas sejam desenvolvidas ou que essas instituições sejam reorganizadas internamente, para sanar as omissões existentes. Nas palavras de Campos (2016, p. 189), esses provimentos jurisdicionais são "comandos voltados a alcançar as mudanças institucionais que caracterizam a public law litigation".

Assim, conforme preleciona Fiss (2017, p. 590), quando a instância judicial recorre à sentença estrutural, o comum é que o próprio arranjo burocrático, responsável por formular e executar políticas públicas, encontre-se com graves problemas, razão pela qual o Judiciário intervém para promover uma reorganização que leve essa estrutura fragilizada para dentro dos limites constitucionais. São decisões que se orientam para uma perspectiva futura, e não apenas em curto prazo, evitando que a sentença se converta em um problema maior do que o original (SALAZAR; MEIRELES, 2017, p. 32). Afinal, por tratarem de questões complexas e de difícil resolução, o legado das decisões estruturais não deve ser aferido apenas pela resolução imediata do caso concreto ao qual foi aplicada. Como explicam Fachin e Bueno (2018, p. 25), "provimentos desta complexidade tem, por consequência, efeitos também complexos e que assim devem ser apreendidos". Quando essas sentenças são utilizadas, dois riscos principais costumam ser levantados: primeiro, a incompetência técnica do Judiciário em intervir na formulação de políticas públicas; em segundo lugar, a falta da legitimidade dos órgãos judiciais em alterar escolhas feitas por setores políticos que têm legitimidade de investidura (VITORELLI, 2017, p. 372).

Tentando classificar as diferentes formas de intervenção judicial na esfera dos poderes políticos, Tushnet (2008, p. 20-21) afirma que existem dois modelos principais: o strong-form review e o weak-form review. Ainda que toda classificação seja artificial, visto que a realidade em si mesma é hipercomplexa, não possuindo essas segmentações (MACHADO SEGUNDO, 2016, p. 42-44), é útil subdividir esses provimentos em grupos diversos, para estudar melhor as características específicas de cada sentença estrutural, bem como os seus efeitos, vantagens e desvantagens. Importante ressaltar que esses modelos não existem de forma pura na realidade, mas funcionam como tipos ideais weberianos, ou seja, focam em determinadas 
características da realidade em detrimento de outras, para facilitar a sua compreensão (NEVES, 2014, p. 101-102).

No strong-form review, a chance de uma intervenção jurisdicional ineficiente e violadora da separação de poderes é consideravelmente maior. Isso porque, nesse modelo, o Judiciário dá a última palavra sobre a solução das omissões estatais (TUSHNET, 2008, p. 21), influenciando diretamente na formulação de políticas públicas. O órgão judicial responsável pela questão atua de forma solipsista, determinando, em grande parte, como o Poder Público deve agir. Exemplo desse modelo são as structural injunctions, utilizadas pela Suprema Corte Americana para determinar profundas mudanças em instituições públicas e privadas (JOBIM, 2013, p. 91-93).

Em contrapartida, no weak-form review, busca-se a construção de um diálogo institucional entre os setores políticos e o Judiciário, com o intuito de retirar deste Poder o monopólio sobre a interpretação dos dispositivos constitucionais envolvidos no litígio (RAY, 2016, p. 24). Consequentemente, as instâncias judiciais respeitam as funções típicas da Administração Pública e não intentam formular, unilateralmente, as medidas que devem ser adotadas para a superação das omissões políticas.

Por fim, tem-se o experimentalismo, defendido por Sabel e Simon $(2004,1.019)$ como um desdobramento do weak-form review ${ }^{3}$. No paradigma experimentalista, as Cortes abandonam o seu papel tradicional de apenas julgar, procurando estimular processos deliberativos que envolvam os apartes e outros grupos interessados no litígio, para desenvolverem e implementarem os seus direitos (LIEBENBERG; YOUNG, 2014, p 237). Portanto, a sua característica distintiva é a grande abertura à participação, tanto do segmento populacional afetado pela omissão política, como das instituições, públicas e privadas, interessadas na demanda estrutural. O Compromisso Significativo, sentença estrutural desenvolvidas pela Corte Constitucional da África do Sul, é uma expressão do experimentalismo (RAY, 2016, p. 24).

Ciente dos três principais paradigmas que orientam a utilização das sentenças estruturais, resta saber qual desses modelos tem exercido uma maior influência no Brasil e como os processos estruturais têm se desenvolvido no País.

\subsection{Os processos estruturais no Brasil}

É crescente o número de estudos publicados no país sobre processos estruturais. Os fundamentos desses litígios, no entanto, não são novidade no Supremo Tribunal Federal (STF), que já tratou, em diversas circunstâncias, sobre a possibilidade de intervenção do Judiciário no âmbito de atuação dos poderes políticos.

${ }^{3}$ Tushnet (2008, p. 249) identifica o experimentalismo como uma variante do modelo fraco de revisão judicial. 
Importante caso levado ao STF, e que contribuiu para fixar a base jurídica para o desenvolvimento dos processos estruturais, foi a ADPF $n^{\circ} 45$, na qual o relator, ministro Celso de Mello, apresentou a tese de que seria possível determinar medidas, para o Executivo, quando o mínimo existencial dos detentos de determinando estabelecimento prisional estivesse sendo violado (FERRAZ, 2014, p. 125). Além disso, o ministro argumentou que o Executivo e o Legislativo não tinham irrestrita liberdade de atuação, cabendo ao Judiciário resguardar o mínimo existencial ameaçado pelas omissões estatais (BRASIL, 2004).

Com base nesses argumentos, o Tribunal, no julgamento do RE no 592.581, consignou que o Judiciário pode determinar que a Administração Pública realize reformas emergenciais em presídios para assegurar o mínimo existencial dos detentos. É nesse sentido o teor do tema no 220, de repercussão geral e oriundo do julgamento do referido Recurso Extraordinário. Por meio desse enunciado, o STF deixa claro que há "Competência do Poder Judiciário para determinar ao Poder Executivo a realização de obrar em estabelecimentos prisionais com o objetivo de assegurar a observância de direitos fundamentais dos presos" (BRASIL, 2015a).

Ainda que tais casos tenham propiciado uma maior intervenção judicial na elaboração e execução de políticas públicas, o principal marco para os processos estruturais foi o reconhecimento do Estado de Coisas Inconstitucional ${ }^{4}$ (ECI) do sistema prisional, no julgamento da medida cautelar da ADPF nº 347/DF, em 2015. A partir dessa decisão, multiplicaram-se os trabalhos que versam sobre litígios estruturais e o ECI. A razão para essa viragem é o ineditismo da decisão: pela primeira vez o STF reconhece expressamente a utilização de uma sentença estrutural estrangeira, destinada a modificar um conjunto de instituições públicas (PEREIRA; GONÇALVES, 2015, p. 146).

Analisando os pedidos cautelares da ação, o relator, ministro Marco Aurélio, determinou que os juízes e tribunais, dentre outras medidas, estabelecessem, quando possível, penas alternativas à prisão, e que a União liberasse o saldo acumulado do Fundo Penitenciário Nacional, abstendo-se de realizar novos contingenciamentos (VIEIRA JÚNIOR, 2015 p. 19).

Já nos pedidos finais, o PSOL requer, dentre outros pleitos: que o STF reconheça o Estado de Coisas Inconstitucional do sistema prisional; que o Governo Federal elabore e encaminhe ao STF, no prazo máximo de 3 meses, um Plano Nacional visando a superação do ECI do sistema penitenciário brasileiro, dentro de um prazo de 3 anos; que o STF delibere sobre o Plano Nacional, para homologá-lo ou impor medidas alternativas ou complementares, que reputar necessárias para a superação do crise (BRASIL, 2015b, p. 70-73).

Diante dos pedidos formulados na ação, é possível constatar que o eventual deferimento transformará o STF em uma instância revisora dos trabalhos do

${ }^{4} \mathrm{O}$ ECI é uma sentença estrutural utilizada pela Corte Constitucional da Colômbia quando há uma série de profundas violações aos direitos fundamentais de determinado segmento populacional, decorrente de ações e omissões dos órgãos estatais (CAMPOS, 2016, p.189). 
Executivo. Afinal, o Tribunal poderá alterar ou complementar os planos que serão formulados com quaisquer medidas que, em seu entender, sejam necessárias, podendo ignorar até as análises técnicas desenvolvidas pelos órgãos administrativos competentes. Por essa razão, Vieira e Bezerra (2016, p. 221), analisando a adoção do ECI na ADPF no 347/DF, afirmam que a forma como o instituto foi adotado no País, sem considerar a premente necessidade de promover um redesenho institucional, acaba por esvaziá-lo. É esse também o pensamento de Magalhães (2019, p. 31-32), que afirma:

Do ponto de vista dogmático, não é tarefa simples explicar a inserção do ECI no direito constitucional brasileiro. A decisão do STF na ADPF 347 é inconsistente na caracterização dos pressupostos que justificariam a declaração de um ECI, as medidas cautelares deferidas são pouco efetivas, há uma injustificada demora no julgamento do mérito, os poderes apresentaram respostas pouco substantivas e que seguem a mesma natureza das políticas tradicionalmente desenvolvidas no Brasil e a capacidade de uma Corte Suprema mudar um estado fático de coisas por meio do Direito é posta em dúvida.

Ainda que os pedidos finais da ação não tenham sido julgados, já existem outras tentativas de utilizar o ECI. Em 07/05/2020, o Conselho Federal da OAB ajuizou a ADPF nº 682, pleiteando a suspensão das autorizações para criação de novos cursos jurídicos que ainda não iniciaram o seu funcionamento, bem como vetar a abertura de novas vagas em instituições privadas. Dentre os pleitos apresentados, a entidade requer ao Tribunal "Reconhecer o Estado de Coisas Inconstitucional referente à situação do ensino jurídico, em decorrência da violação sistemática ao preceito constitucional que garante a qualidade do ensino jurídico superior (art. 209, CF)." (BRASIL, 2020, p. 70).

Tendo em vista os ricos decorrentes de uma má utilização do ECI, o senador Antônio Carlos Valadares apresentou, em 11 de novembro de 2015, o Projeto de Lei do Senado (PLS) no 736/2015 (BRASIL, 2015c), o qual, além de estabelecer pressupostos objetivos a serem observados pelo tribunal para o reconhecimento do ECI, determinava também que o reconhecimento desse estado de coisas implicasse na celebração de um Compromisso Significativo entre o Poder Público e os segmentos populacionais afetados.

Os pedidos finais formulados na ADPF n 347/DF afastam o STF de um modelo dialógico de sentença estrutural. Pelo contrário, podem conceder excessivo poder ao Tribunal, aprofundados as críticas tradicionalmente feitas aos processos estruturais. À vista disso, é necessário buscar uma alternativa para os litígios estruturais no país, de tal forma que o Judiciário possa promover a efetivação dos 
direitos socioeconômicos, sem tomar para si a função de elaborar as políticas públicas exigidas pelo caso concreto.

\section{O EQUILÍBRIO ENTRE EFICIÊNCIA E LEGITIMIDADE: A ALTERNATIVA DO ATIVISMO JUDICIAL DIALÓGICO}

Sem dúvidas, um dos tópicos mais controversos, quando se trata de processos estruturais, é o papel que o Judiciário deve desempenhar na sua resolução. Qual deve ser a postura do Judiciário, em especial da jurisdição constitucional, ao julgar essas demandas? Como obter uma decisão eficiente, mas respeitando a separação de poderes e a legitimidade democrática?

A resposta a essas perguntas está diretamente ligada ao dilema da justiciabilidade dos direitos sociais (MICHELMAN, 2003, p. 16). Com a constitucionalização desses direitos, o Judiciário deve escolher entre uma postura ativista ou de autoconstrição, decisão que sempre leva ou ao embaraço, ou ao descrédito institucional. Por um lado, a instância judicial intervém diretamente na formulação de políticas públicas, ainda que não tenha a capacidade técnica necessária para reorganizar as prioridades do orçamento público e que contrarie a vontade política majoritária. Por outro, adotando uma postura deferente, o Judiciário pode esvaziar todo o conteúdo normativo dos direitos socioeconômicos, deixando-os dependentes da discricionariedade do Poder Público.

O presente trabalho, no entanto, defende a existência de uma alternativa para o dilema da justiciabilidade. O Judiciário pode atuar de forma consentânea à separação de poderes, sem formular políticas públicas, e ao mesmo tempo promover a concretização dos direitos socioeconômicos (ROACH, 2004, p. 103-104). Assim, a solução estaria no que alguns juristas têm chamado de ativismo judicial dialógico (LIMA; FRANÇA, 2019, p. 230-231).

À primeira vista, essa resposta pode incomodar alguns leitores. Isso porque o termo ativismo judicial tem sido utilizado como um trunfo argumentativo. Em discussões sobre a validade ou a legitimidade de uma decisão judicial, tão logo um dos debatedores consiga enquadrá-la como ativista, muitos dão a questão por encerrada, como se, na essência da palavra ativismo, estivesse presente a própria inconstitucionalidade (KLARE, 2014, p. 5).

Isso, entretanto, não é verdade. Rodrigues e Arantes (2020, p. 25-26), analisando a abertura semântica da expressão, aponta que, a depender do autor utilizado, têmse diversos tipos de ativismo judicial, cuja classificação depende dos diferentes fatores que motivam a atuação do órgão jurisdicional. Consequentemente, não é possível, aprioristicamente, atribuir um caráter patológico à expressão. A sua adequação à ordem jurídico-constitucional irá depender não do termo ativismo, mas da forma como ele se manifesta e da fundamentação utilizada na decisão. Apesar de não caber neste trabalho um resgaste histórico da evolução do papel da atividade jurisdicional, destaca-se, como aduz Felipe Braga Albuquerque, que o juiz moderno não se prende à característica de manutenção de uma classe 
dominante, inclusive porque o Judiciário goza de independência na estrutura estatal (2013, p.81).

É nesse mesmo sentido o pensamento de Oscar Vilhena, que defende uma diferenciação entre responsividade e usurpação. A responsividade está associada à ideia de que o Judiciário deve atuar ativamente para promover a efetividade dos dispositivos constitucionais e, em especial, dos direitos fundamentais (VIEIRA, 2018, p. 175). Por essa razão, ela depende do arcabouço institucional e pode ser legítima, não implicando, necessariamente, em usurpação. Esclarecendo a diferença, o autor explica:
A responsividade não deve ser confundida com a usurpação, em que o Judiciário avança, sem a devida justificativa normativa, sobre a função de outros poderes, e não com a finalidade de emitir um juízo normativo sobre a validade de determinados atos normas em relação à Constituição, mas com o objetivo de substituir decisões políticas ou técnicas tomadas pelos demais poderes por seus próprios juízos técnicos ou políticos (VIEIRA, 2018, p. 175-176).

Dessa forma, adota-se um conceito mais amplo de ativismo judicial, o qual é defendido por Campos (2014, p. 347): podem ser assim adjetivadas as decisões que manifestam uma autoexpansão do papel político-institucional do Judiciário em face dos outros Poderes. Se essa é uma expansão constitucional ou não, irá depender do contexto no qual a decisão foi proferida. $O$ autor também afirma que "[...] o ativismo judicial não pode ser considerado aprioristicamente ilegítimo, pois isso depende dos diferentes fatores envolvidos e da dimensão decisória manifestada" (CAMPOS, 2016, p. 15), de maneira que apenas a dimensão antidialógica, constituída por uma supremacia judicial e uma recusa a dialogar com os outros Poderes, deve ser tida como manifestação judicial ilegítima.

Logo, deve-se afastar eventuais preconceitos e antipatias em relação ao ativismo judicial dialógico, visto que essa postura intenta justamente afastar as principais críticas feitas às condutas excessivamente proativas do Judiciário. As sentenças dialógicas definem as metas e os caminhos para a implementação de políticas públicas, acompanhando o progresso do cumprimento das sentenças e deixando as decisões mais importantes para as agências governamentais (CHAGAS et al, 2015, p. 2.206).

Consequentemente, ao adotar uma postura ativista, mas dialogal, o Judiciário não usurparia os poderes administrativos ou legislativos (MARMELSTEIN, 2015b, p. 250-251). O foco seria construir um diálogo institucional, para que os entes estatais responsáveis atuem conforme as suas atribuições típicas, construindo soluções adequadas dentro de suas esferas de competência. 
Sendo assim, o ativismo dialógico se enquadra na ideia de constitucionalismo cooperativo, o qual também é fundamental para a pesquisa aqui desenvolvida. Elucidando o termo, Vanice Valle e Cecilia Silva (2009, p. 331) explicam que:

Importa o constitucionalismo cooperativo portanto, na afirmação de que, ainda que se tenha em conta a supremacia da constituição, e que a proteção desse valor se tenha confiada ao judiciário; disso não decorre a exclusão da possibilidade/utilidade do compartilhamento com as demais estruturas do poder, das distintas tarefas envolvidas no resultado final "efetividade de direitos". Ao contrário, essa se revelaria a estratégia mais legítima do cumprimento desse mister, afastando como possibilidade a adoção de uma judicial review encerrada no isolacionismo da supremacia clássica, hermética e não cooperativa.

E quais as vantagens desse cooperativismo constitucional? Mais especificamente, como ele pode contribuir para superar as críticas feitas à utilização das sentenças estruturais?

Primeiramente, uma decisão que promove o diálogo institucional possibilita uma maior reflexão e compreensão do problema enfrentado, evitando que o Judiciário imponha medidas paliativas e pouco eficientes. Ariza (2013, p. 151), tendo como base a experiência colombiana na utilização de sentenças estruturais, defende que a falta de diálogo, juntamente com intervenções judiciais rígidas e unilaterais, pode comprometer a eficiência do processo estrutural, fazendo com que as medidas adotadas tenham caráter paliativo.

Em segundo lugar, há uma maior legitimidade na atuação judicial. Para interferir nas decisões dos poderes políticos, sem violar o princípio da separação de poderes, o diálogo institucional é imprescindível, não apenas em razão do anseio de produzir decisões mais bem fundamentadas e com maior chance de serem executadas, mas se torna conduta necessária a fim de conferir maior legitimidade às decisões judiciais (MAIA, 2018, p. 82). Quando uma Corte adota o ativismo dialógico, funciona como uma verdadeira força motriz que retira os setores políticos da sua inércia, fixando metas e parâmetros constitucionais a serem observados pelo Executivo, mas não impõe quais políticas públicas devem ser realizadas. Os detalhes orçamentários permanecem com os Poderes competentes para tanto, ou seja, o Executivo e o Legislativo.

A consequência desse respeito à separação de poderes e às esferas de competência da Administração Pública é um maior comprometimento dos setores políticos com a solução do litígio estrutural e, como resultado, uma menor 
possibilidade de ocorrência do efeito backlash ${ }^{5}$. Seria possível enquadrar o ativismo dialógico no weak-form review, que favorece o comprometimento das instâncias políticas com a decisão judicial (TUSHNET, 2017, p. 59-61). Sem o engajamento dos órgãos políticos, as sentenças estruturais tendem ao fracasso e, quanto maior a ingerência do Judiciário no âmbito de atuação dos demais órgãos estatais, maiores as chances de ineficiência da decisão (SARLET, 2017, p. 227-228).

Na medida em que o Judiciário aponta o problema, mas possibilita que ele seja solucionado pelo Executivo, há um maior engajamento com a efetividade da decisão. Afinal, é uma possibilidade de solucionar o problema sem uma maior ingerência dos órgãos jurisdicionais. Além disso, outro fator que contribui para o engajamento dos setores políticos é a possibilidade de que eles ganhem mais crédito pela solução implementada (SARLET, 2017, p. 230), visto que possuem uma maior margem de discricionariedade para sua atuação.

A intenção deste trabalho, contudo, é ir além do weak-form review. Acredita-se que o cooperativismo constitucional e o diálogo institucional criado nas sentenças estruturais devem englobar não só o Judiciário e os órgãos do Poder Público responsáveis por elaborar e executar políticas públicas, mas também os segmentos populacionais afetados pela omissão política. Ouvir esses grupos sociais, geralmente sub-representados na arena política, pode contribuir significativamente para a eficiência e a legitimidade do processo estrutural.

Segundo Gloppen (2005, p. 3-4), o sucesso dos litígios estruturais depende de quatro fatores: a possibilidade de os grupos afetados terem voz e acesso ao Judiciário; a capacidade de resposta dos tribunais demandados, aceitando essas demandas; a habilidade dos juízes para encontrar meios legais adequados para assegurar os direitos econômicos e sociais; e o comprometimento das autoridades políticas com o cumprimento da decisão proferida nesses litígios. Para a autora, é fundamental que haja uma maior participação da população afetada na superação da omissão política. Assim, em um modelo de democracia deliberativa, as Cortes podem se tornar um ambiente institucionalizado para ouvir as vozes marginalizadas e chamar a atenção para os seus clamores (LIEBENBERG, 2012, p. $11)$.

A participação popular, enquanto instrumento de manejo do dissenso nas deliberações judiciais, parece indispensável para que boas escolhas públicas sejam tomadas. Conforme afirmam Bittencourt e Reck (2018, p. 64), não se pode delegar essas "[...] difíceis escolhas a uma visão unilateral, solipsista, mas que sejam

${ }^{5} \mathrm{O}$ termo tem sido utilizado para designar uma contundente reação contrária a decisões judiciais consideradas excessivamente progressistas, e que pode advir tanto da sociedade quanto dos poderes políticos instituídos, comprometendo a eficiência da sentença proferida. O fenômeno tende a ocorrer quando uma decisão diverge consideravelmente da normatização consagrada socialmente ou das instituições em relação às quais segmentos influentes da população mantenham uma significativa fidelidade normativa (KOZICKI, 2015, p. 194). 
construídas comunicativamente, a partir do debate e da participação dos diversos atores".

Tudo que foi até então trabalhado revela a importância da deliberação coletiva para as escolhas públicas, que viabiliza um processo de tomada de decisão, no qual as alternativas não são definitivas e imutáveis, mas se tratam de possibilidades, passíveis de constante rediscussão (ZAGREBELSKY, 2011, p. 135). Por essa razão, as Cortes, em processos estruturais, constituem verdadeiros fóruns deliberativos: não porque vão formular políticas públicas unilateralmente, mas porque irão promover a construção de um diálogo institucional, incluindo-se aí os segmentos populacionais afetados pela atuação estatal.

Portanto, defende-se, como modelo ideal para as sentenças estruturais, não o weak-form review, mas o democratic experimentalism, que, além das características típicas do weak-form, apresenta, como elemento distintivo, a grande abertura à participação tanto do grupo social afetado pela omissão, quanto das instituições, públicas e privadas, interessadas na demanda estrutural. A utilização de sentenças estruturais dialógicas, todavia, exige que sejam fixadas diretrizes que orientem a atuação do Judiciário e das partes envolvidas no litígio. O próximo tópico se destina ao estudo de uma das principais teorias que foram desenvolvidas para fornecer as referidas diretrizes.

4. AVALIANDO A QUALIDADE DE UMA SENTENÇA ESTRUTURAL DIALÓGICA: AS DIRETRIZES NORMATIVAS DE SUSAN STURM

Diante dos argumentos apresentados, seria possível questionar: defender a democratização dos processos estruturais como formula mágica para o seu aprimoramento não é uma solução ingênua? A inclusão dos grupos afetados seria uma resposta suficiente às críticas a essas demandas? Ciente desses questionamentos, Liebenberg faz um alerta importante. A democratização dos processos estruturais não é uma panaceia, uma solução milagrosa que, subitamente, resolve todos os problemas dessa espécie de litígio, tornando-o eficiente (LIEBENBERG, 2018, p. 649). É necessário estruturar, cuidadosamente, o diálogo institucional e a participação dos grupos afetados.

De fato, é ingênuo acreditar que a participação, por si só, garante a obtenção de bons resultados, já que pode ser realizada de forma inadequada, tão somente para simular um diálogo com a comunidade afetada (WILLIAMS, 2006, p. 203). Apenas quando as necessidades das pessoas são escutadas e, efetivamente, influenciam a implementação de políticas públicas, é que a participação pode ser considerada como significativa. Portanto, é necessário estruturar, cuidadosamente, o diálogo institucional e a participação dos grupos afetados.

Dito isso, um trabalho que defende a utilização de uma sentença estrutural dialógica precisa fixar diretrizes normativas que orientem a sua utilização e contribuam para a qualidade da participação dos grupos afetados. É essa a preocupação de Susan Sturm, que desenvolveu uma teoria normativa sobre como 
os remédios estruturais devem ser manejados (MAHOMEDY, 2019, p. 28). As diretrizes seriam: participação, respeito à separação de poderes, imparcialidade, fundamentação adequada das decisões e remediação.

O primeiro critério apontado por Sturm é a participação. Os grupos que são afetados pela implementação de um remédio estrutural, ou que são responsáveis por essa implementação, devem ter a oportunidade de influenciar, significativamente, os desenvolvimentos das medidas que serão implementadas (STURM, 1991, p. 1410). Complementando esse pensamento, Chenwi (2014, p. 178) afirma que o direito à participação é uma decorrência dos direitos socioeconômicos, que são fundamentais para o fortalecimento de uma democracia deliberativa.

Para Sturm, a participação tem dois propósitos principais. Primeiro, assegurar a dignidade das partes que são afetadas pelo litígio, que serão tratadas como parceiras na construção de soluções efetivas (STURM, 1991, p. 1392). Segundo, a participação na elaboração das políticas públicas contribui para que as partes, e em especial o Poder Público, engajem-se na efetivação do remédio estrutural (STURM, 1991, p. 1393). Swanopel (2017, p. 24) acrescenta que a participação diminui o ônus da legitimidade sobre o Judiciário, já que os juízes não serão os responsáveis por formular as políticas públicas.

A autora chama atenção, no entanto, para a necessidade de que a participação ocorra de uma forma que mitigue o desequilíbrio entre o poder de barganha das diferentes partes. Para assegurar a igualdade nas negociações, o Judiciário desempenha um papel fundamental. Assim, Sturm (1991, p. 1396) afirma que:

Finalmente, a participação pode ajudar as várias partes interessadas no processo de reparação pública que não têm capacidade de participar efetivamente da reparação pública. tomando uma decisão. Os litigantes são frequentemente pobres, politicamente impotentes e desorganizados e, portanto, podem ser menos capazes de influenciar a decisão corretiva. No entanto, os valores atendidos pela participação no estágio corretivo dependem de um envolvimento direto daqueles que serão afetados pelos resultados. Um importante critério de participação corretiva, portanto, é a capacidade de um determinado remédio participativo para controlar desigualdades de poder, recursos e sofisticação ${ }^{6}$.

${ }^{6}$ Finally, participation can aid the various stakeholders in the public remedial process who lack the capacity to participate effectively in public remedial decisionmaking. The plaintiffs frequently are poor, politically powerless, and unorganized, and thus may be less able to influence the remedial decision. Yet, the values served by participation at the remedial stage depend on some direct involvement by those who must live with the results. An important criteria of remedial participation, therefore, is the capacity of a particular form of remedial practice to control for unequal power, resources, and sophistication. 
Para contornar o problema do desequilíbrio, Sturm aponta algumas possibilidades. Uma boa alternativa para equalizar o poder de barganha é a representação dos grupos sociais mais vulneráveis, ou seja, estes segmentos sociais seriam auxiliados por instituições tecnicamente capacitadas, que possuem experiência na defesa dos direitos fundamentais discutidos no litígio. Susan aponta a importância de que esses representantes ajam com accountability, isto é, não só deem satisfações para a comunidade representada, mas também ajam com responsabilidade ao exercer a representação, buscando defender, da melhor forma possível, os interesses dos representados (STURM, 1991, p. 1410). Outra importante medida é adotar formas de interação que promovam a cooperação e o consenso, abandonando a trágica concepção adversarial dos processos judiciais (STURM, 1991, p. 1410). O Judiciário também possui um papel relevante para a equalização, exercendo uma função de supervisão das negociações a serem desenvolvidas. A instância judicial deve assegurar um procedimento deliberativo justo e equitativo, e não uma mera imposição das vontades de uma parte sobre a outra (SCOTT; STURM, 2006, p. 565-566).

Quanto ao segundo critério, o respeito à separação de poderes, Sturm (1991, p. 1410) afirma que qualquer sentença estrutural deve se preocupar com o respeito às competências das instituições governamentais envolvidas no processo. Com a crescente inclusão dos direitos socioeconômicos nos textos constitucionais, o debate não deve ser sobre a sua exigibilidade judicial, mas como os tribunais devem exercer o seu dever de proteger esses direitos. Para contornar a crítica de que o Judiciário carece de legitimidade para aplicar remédios estruturais, Sturm (1991, p. 1405) afirma que as instâncias judiciais devem respeitar a integridade dos órgãos públicos, ou seja, as suas competências típicas. Caso o Judiciário extrapole os seus limites, isso pode comprometer a legitimidade da sentença, e até mesmo a sua eficácia (STURM, 1991, p. 1403-1404). Permitir uma efetiva participação é fundamental para mitigar as críticas de que a intervenção judicial violou a separação de poderes (SWANEPOEL, 2017, p. 24).

Em terceiro lugar, os juízes devem ter muito cuidado ao proferirem sentenças estruturais, buscando sempre a imparcialidade e a objetividade na tomada de decisão (STURM, 1991, p. 1397-1398). A parcialidade do juiz, condicionada por concepções prévias sobre o caso, pode comprometer a eficácia da participação pública, já que o julgador pode querer impor às partes as soluções que ele julga como mais adequadas (STURM, 1991, p. 1397).

Tratando do tema, Vitorelli apresenta a influência dos vieses $\operatorname{cognitivos}^{7}$ no discernimento do juiz envolvido em um litígio estrutural. Como o autor destaca,

${ }^{7} \mathrm{O}$ viés cognitivo, também chamado de heurística, é um atalho mental que pode levar a desvios de racionalidade. Ele ocorre quando a mente cria padrões, baseada em experiências prévias, que condicionam os julgamentos futuros de um indivíduo. Assim, funcionam como atalhos mentais, 
existem várias pré-compreensões que podem condicionar a interpretação do juiz, facilitando a sua adesão, ainda que inconsciente, aos interesses de uma das partes do litígio (VITORELLI, 2017, p. 384-385). Tendo em vista a complexidade dos processos estruturais, que comportam uma diversidade de interesses, a influência dessas heurísticas pode ser prejudicial. Por causa disso o autor alerta que o juiz precisa estar ciente desses riscos, bem como das técnicas que podem ser utilizadas para diminuir a influência dos diferentes vieses (VITORELLI, 2017, p. 390-391).

O quarto critério é a exigência de uma decisão fundamentada, para justificar o remédio estrutural escolhido (STURM, 1991, p. 1411). O tribunal deve especificar as razões que o motivaram a proferir uma sentença estrutural, e essa argumentação deve se basear tanto em considerações empíricas, levando em conta as circunstâncias do caso concreto, como em disposições normativas e precedentes judiciais, responsáveis por demonstrar a adequação jurídica da escolha (STURM, 1991, p. 1411). Como bem alerta Liebenberg (2016, p. 8), a falha em atender esse princípio pode deixar o tribunal vulnerável às acusações de que o Judiciário está usando indevidamente o seu poder coercitivo, sem uma devida justificação. Portanto, a observância dessa diretriz contribui para atender à exigência de imparcialidade (STURM, 1991, p. 1411), e auxilia o Judiciário a tomar melhores decisões em futuros processos estruturais, que tratem de casos semelhantes.

Por fim, Sturm defende a remediação: a sentença estrutural escolhida deve ser apta a, efetivamente, promover a proteção dos direitos fundamentais violados. É importante deixar claro quais os direitos violados pelo Poder Público, quais as obrigações das partes, e porque o remédio escolhido é o mais adequado, tendo em vista o caso concreto e os interesses conflitantes (STURM, 1991, p. 1399). Sturm (1991, p. 1430) também ressalta a importância de fixar critérios para avaliar as medidas que serão implementadas, e que o tribunal faça isso em diálogo com as partes.

\section{CONCLUSÃO}

Com base no que foi exposto neste artigo, é possível formular algumas conclusões. Primeiramente, a intenção deste trabalho não é negar a importância dos processos estruturais, tampouco a necessidade de uma intervenção judicial para sanar as omissões políticas existentes. Defender isso é o mesmo que atestar o vazio normativo dos direitos socioeconômicos: eles criariam deveres para o Estado, mas não haveria quem pudesse exigir que tais obrigações fossem observadas.

Isso não significa, contudo, que o caminho a ser seguido é o do strong-form review. O Judiciário deve lembrar que carece não só de legitimidade para determinar, de forma solipsista, as prioridades orçamentárias do Poder Público, ou quais políticas públicas devem ser executadas para viabilizar uma reforma

viabilizando a redução da complexidade da realidade e permitindo que decisões sejam tomadas de forma mais rápida (TVERSKY; KAHNEMAN, 1974, p. 1124). 
estrutural. E mais do que isso: as instâncias judiciais carecem de competências técnicas para elaborar políticas públicas e, caso tentem realizar essa tarefa, há uma grande chance de tornar o processo estrutural ineficiente.

Dessa forma, a intenção deste artigo é mostrar que há uma alternativa para o dilema da justiciabilidade: a utilização de sentença estruturais participativas, conforme o experimentalismo democrático. Nessa perspectiva, o Judiciário iria funcionar como uma força motriz que retira o Poder Público da sua inércia, determinando quais os direitos fundamentais violados e supervisionando a atuação estatal na solução da omissão política. Em vez de agir de forma unilateral, a intervenção judicial ocorreria de forma dialógica com a Administração Pública, incluindo-se no diálogo os segmentos sociais afetados pelas omissões.

Por fim, constatou-se que a teoria de Susan Sturm fornece importantes contribuições para a construção de uma sentença estrutural dialógica eficaz. A autora ressalta a importância do direito à participação, e como a inclusão dos grupos afetados pode contribuir para amenizar as críticas feitas aos processos estruturais, conferindo-lhe maior legitimidade. Além disso, aponta a necessidade de equalizar as partes envolvidas no litígio, e como deve ocorrer a fundamentação de uma sentença estrutural. Com bases nas diretrizes da autora, o Judiciário brasileiro pode aprimorar a sua atuação em litígios estruturais, tendo a oportunidade de contornar as críticas que dificultam uma melhor proteção dos direitos socioeconômicos.

\section{REFERÊNCIAS}

ALBUQUERQUE, Felipe Braga. Direito e Política: Pressupostos para a análise de questões políticas pelo judiciário à luz do princípio democrático. Florianópolis: Conceito, 2013.

ARENHART, Sérgio Cruz. Processo multipolar, participação e representação de interesses concorrentes. In: ARENHART, Sérgio Cruz; JOBIM, Marco Félix (Org.). Processos estruturais. Salvador: JusPodivm, 2017. p. 423-448, p. 423-424.

ARIZA, Libardo José. The Economic and Social Rights of Prisoners and Constitutional Court Intervention in the Penitentiary System in Colombia. In: MALDONADO, Daniel Bonilla. Constitutionalism of the Global South: The activist tribunals of India, South Africa, and Colombia. New York: Cambridge University Press, 2013. p. 129-162.

BEATTY, David M.. A essência do Estado de direito. Tradução: Ana Aguiar Cotrim. São Paulo: WMF Martins Fontes, 2014. 
BRASIL. Projeto de Lei do Senado no 736/2015. Altera as Leis no 9.882, de 3 de dezembro de 1999, e 13.105, de 16 de março de 2015, para estabelecer termos e limites ao exercício do controle concentrado e difuso de constitucionalidade pelo Supremo Tribunal Federal, dispor sobre o estado de coisas inconstitucional e o compromisso significativo. Brasília, 2015c. Disponível em: https://www25.senado.leg.br/web/atividade/materias/-/materia/124010. Acesso em: 02 jan. 2020.

BRASIL. Supremo Tribunal Federal. Arguição de Descumprimento de Preceito Fundamental no 45/DF. Relator: Ministro Celso de Mello. Diário Oficial da União. Brasília, 2004. Disponível em: http://www.sbdp.org.br/arquivos/material/343_204\%20ADPF\%202045.pdf. Acesso em: 17 abr. 2020.

BRASIL. Supremo Tribunal Federal. Arguição de Descumprimento de Preceito Fundamental no 682. Relator: Ministro Ricardo Lewandowski. Diário Oficial da União. Brasília, 2020. Disponível em: https://www.jota.info/wpcontent/uploads/2020/05/oab-suspensao-cursos-de-direito.pdf. Acesso em: 09 mai. 2020.

BRASIL. Supremo Tribunal Federal. Arguição de Descumprimento de Preceito Fundamental № 347/DF. Relator: Ministro Celso de Mello. Diário Oficial da União. Brasília, 2015b. Disponível em: http://www.jota.info/wpcontent/uploads/2015/05/ADPF-347.pdf. Acesso em: 25 abr. 2020.

BRASIL. Supremo Tribunal Federal. Recurso Extraordinário no 592.581. Relator: Ministro Ricardo Lewandowski. Diário Oficial da União. Brasília, 2015a. Disponível em:

http://www.stf.jus.br/portal/jurisprudenciaRepercussao/verAndamentoProcesso.a sp?incidente $=2637302 \&$ numeroProcesso $=592581 \&$ classeProcesso $=$ RE $\&$ numeroTe $\mathrm{ma}=220$. Acesso em: 17 abr. 2020.

BITENCOURT, Caroline Müller; RECK, Janriê Rodrigues. Formulação e execução de políticas sociais no cenário brasileiro a partir de uma ação comunicativa: Atores sociais. In: BITENCOURT, Caroline Müller; RECK, Janriê Rodrigues. Abordagens Epistemológicas sobre Democracia, Políticas Públicas e Controle Social. Santa Cruz do Sul: Essere Nel Mondo, 2018. p. 64-83.

BUENO, C. C. ; FACHIN, Melina Girardi . Decisões estruturantes na jurisdição constitucional brasileira: critérios processuais da tutela jurisdicional de direitos prestacionais. Revista de Estudos Institucionais, v. 4, p. 211-246, 2018. 
CAMPOS, Carlos Alexandre de Azevedo. Dimensões do Ativismo Judicial do STF. Rio de Janeiro: Forense, 2014.

CHAGAS, Tayná Tavares das et al. Estado de coisas inconstitucional: um estudo sobre os casos colombiano e brasileiro. Revista Quaestio Iuris, [s.l.], v. 8, n. 4, p.2.596-2.612, p. 2.206, 26 dez. 2015.

CHENWI, Lilian. Democratizing the socio-economic rights-enforcement process. In: GARCÍA, Helena Alviar; KLARE, Karl; WILLIAMS, Lucy A. (Ed.). Social and Economic Rights in Theory and Practice: Critical Inquiries. Nova York:

Routledge Research In Human Rights Law, 2014. p. 178-196.

FERRAZ, Octavio Luiz Motta. Between activism and deference: social rights adjudication in the Brazilian Supreme Federal Tribunal. In: GARCÍA, Helena Alviar; KLARE, Karl; WILLIAMS, Lucy A. (Ed.). Social and Economic Rights in Theory and Practice: Critical Inquiries. Nova York: Routledge Research In Human Rights Law, 2014. p. 121-137.

FISS, Owen. To make the Constitution a living truth: four lectures on the Structural Injunction. In: ARENHART, Sérgio Cruz; JOBIM, Marco Félix (Org.). Processos Estruturais. Salvador: Juspodivm, 2017. p. 583-607.

\section{GLOPPEN, Siri. Social Rights Litigation as Transformation: South African} Perspectives. Chr. Michelsen Institute, CMI Working Paper WP 2005: 3.

JOBIM, Marco Félix. Medidas Estruturantes: da Suprema Corte Estadunidense ao Supremo Tribunal Federal. Porto Alegre: Livraria do Advogado Editora, 2013.

KLARE, Karl. Criticial perspectives on social and economic rights, democracy and separation of powers. In: GARCÍA, Helena Alviar; KLARE, Karl; WILLIAMS, Lucy A. (Ed.). Social and Economic Rights in Theory and Practice: Critical Inquiries. Nova York: Routledge Research In Human Rights Law, 2014. p. 3-22.

KOZICKI, Katya. Backlash: as "reações contrárias" à decisão do Supremo Tribunal Federal na ADPF no 153. In: SOUZA JÚNIOR, José Geraldo de et al. (Org.). O Direito Achado na Rua: introdução crítica à justiça de transição na América Latina. Brasília: UnB, 2015. v. 7, p. 192-196.

LANDAU, David. The Reality of Social Rights Enforcement. Harvard International Law Journal, v. 53, n. 1, 2012, p. 190-247.

LIEBENBERG, Sandra. Engaging the paradoxes of the universal and particular in human rights adjudication: The possibilities and pitfalls of 'meaningful 
engagement'. African Human Rights Law Journal, Pretoria, v. 12, n. 1, p. 1-29, 2012.

LIEBENBERG, Sandra. Participatory Justice in Social Rights

Adjudication. Human Rights Law Review, [s.l.], v. 18, n. 4, p.623-649, 21 nov. 2018.

LIEBENBERG, Sandra. Remedial principles and meaningful engagement in education rights disputes. PER: Potchefstroomse Elektroniese Regsblad, v. 19, n. 1, p. 1-43, 2016.

LIEBENBERG, Sandra; YOUNG, Katharine G.. Adjudicating social and economic rights: Can democratic experimentalismo help?. In: GARCÍA, Helena Alviar; KLARE, Karl; WILLIAMS, Lucy A. (Ed.). Social and Economic Rights in Theory and Practice: Critical Inquiries. Nova York: Routledge Research In Human Rights Law, 2014. p. 237-257.

LIMA, Flavia; FRANÇA, Eduarda. Ativismo dialógico X Bloqueios institucionais: limites e possibilidades do controle jurisdicional de políticas públicas a partir da sentencia T-025/04 da Corte Colombiana. Argumenta Journal Law, Jacarezinho PR, Brasil, n. 31, 2019, p. 209-243, p. 230-231.

MACHADO SEGUNDO, Hugo de Brito. O direito e sua ciência: uma introdução à epistemologia jurídica. São Paulo: Malheiros, 2016.

MAGALHÃES, Breno Baía. O Estado de Coisas Inconstitucional na ADPF 347 e a sedução do Direito: o impacto da medida cautelar e a resposta dos poderes políticos. Revista Direito GV, [s.1.], v. 15, n. 2, p. 1-37, 2019.

MAHOMEDY, Sameera. The potential of meaningful engagement in realsing socio-economic rights: Addressing quality concerns. 2019. 171 f. Dissertação (Mestrado) - Law, Stellenbosch University, Stellenbosch, 2019.

MARMELSTEIN, George. A eficácia incompleta das normas constitucionais: desfazendo um mal-entendido sobre o parâmetro normativo das omissões inconstitucionais. Revista Jurídica da Fa7, Fortaleza, v. 12, n. 1, p.10-28, p. 25, 2015a.

MARMELSTEIN, George. O Estado de Coisas Inconstitucional: uma análise panorâmica. In: OLIVEIRA, Pedro Augusto de; LEAL, Gabriel Prado (Org.). Diálogo Jurídicos Luso-Brasileiros Volume 1 perspectivas atuais de Direto 
Público: o Direito em tempos de crise. Salvador: Faculdade Baiana de Direito, 2015b, p. 241- 264, p. 250-251.

MAIA, Isabelly Cysne Augusto. Análise da ADPF no 347 e da inadequabilidade do Estado de Coisas Inconstitucional para a efetivação dos serviços públicos: por novos protagonistas na esfera pública democrática. 2018. 177 f. Dissertação (Mestrado) - Curso de Direito, Universidade Federal do Ceará, Fortaleza, 2018.

MICHELMAN, F. I.. The constitution, social rights, and liberal political justification. International Journal Of Constitutional Law, [s.l.], v. 1, n. 1, p. 1334, p. 16, jan. 2003.

NASCIMENTO, F. A. S.. Direitos Fundamentais e sua dimensão objetiva. Porto Alegre: Sergio Antônio Fabris, 2016.

NEVES, Marcelo. Constitucionalização Simbólica e Desconstitucionalização Fática: Mudança Simbólica de Constituição e Permanência das Estruturas Reais de Poder. Revista de Informação Legislativa, Brasília, v. 33, n.132, p. 321-330, 1996.

NEVES, Marcelo. Entre Hidra e Hércules: princípios e regras constitucionais. $2^{\underline{a}}$ ed. São Paulo: WMF Martins Fontes, 2014.

OSNA, Gustavo. Nem "tudo", nem "nada" - decisões estruturais e efeitos jurisdicionais complexos. In: ARENHART, Sérgio Cruz; JOBIM, Marco Félix. Processo Estruturais. Salvador: Juspodivm, 2017. p. 177-202.

PEREIRA, Jane Reis Gonçalves; GONCALVES, Gabriel Accioly . Inconstitucionalidade sistêmica e multidimensional: transformações no diagnóstico das violações à Constituição. JURISPOIESIS, v. 18, p. 130-159, 2015.

RAY, Brian. Engaging with Social Rights: Procedure, Participation, and Democracy in South Africa's Second Wave. Cambridge: Cambridge University Press, 2016.

ROACH, Kent. Dialogic judicial review and its critics. Supreme Court Law Review (2nd), v. 23, p. 49-104, 2004.

RODRIGUES, Fabiana Alves; ARANTES, Rogério Bastos. Supremo Tribunal Federal e a presunção de inocência: ativismo, contexto e ação estratégica. Revista Estudos Institucionais, [s.1.], v. 6, n. 1, p. 21-54, 23 abr. 2020. 
SABEL, Charles F.; SIMON, William H.. Destabilization rights: how public law litigation succeeds. Cambridge: Harvard Law Review, 2004.

SALAZAR, Rodrigo; MEIRELES, Edilton. Decisões estruturais e acesso à justiça. Revista Cidadania e Acesso à Justiça, [s.l.], v. 3, n. 2, p. 21-38, 2 dez. 2017.

SARLET, Ingo Wolfgang. Direito fundamentais sociais e mínimo existencial notas sobre um possível papel das assim chamadas decisões estruturais na perspectiva da jurisdição constitucional. In: ARENHART, Sérgio Cruz; JOBIM, Marco Félix (Org.). Processos Estruturais. Salvador: Juspodivm, 2017. p. 203-232.

SCOTT, Joanne; STURM, Susan. Courts as catalysts: re-thinking the judicial role in new governance. Columbia Journal of European Law, v. 13, p. 565-594, 2006.

STURM, Susan P. A normative theory of public law remedies. Georgetown Law Journal, v. 79, p. 1357-1445, 1991.

SWANEPOEL, Philip. The potential of structural interdicts to constitute effective relief in socio-economic rights cases. 2017. 220 f. Dissertação (Mestrado) - Curso de Direito, Stellenbosch University, Stellenbosch, 2017.

TUSHNET, Mark. A response to David Landau. In: ARENHART, Sérgio Cruz; JOBIM, Marco Félix (Org.). Processos Estruturais. Salvador: Juspodivm, 2017. p. 53-62.

TVERSKY, Amos; KAHNEMAN, Daniel. Judgment under uncertainty: Heuristics and biases. Science, v. 185, n. 4157, p. 1124-1131, 1974.

VIEIRA JUNIOR, R. J. A. Separação de Poderes, Estado de Coisas Inconstitucional e Compromisso Significativo: novas balizas à atuação do Supremo Tribunal Federal. Brasília: Núcleo de Estudos e Pesquisas/CONLEG/Senado, Dezembro/2015 (Texto para Discussão no ${ }^{0}$ 186). Disponível em: https://www12.senado.leg.br/publicacoes/estudoslegislativos/tipos-de-estudos/textos-para-discussao/td186. Acesso em: 09 mai. 2020.

VIEIRA, J. R.; BEZERRA, R.. Estado de coisas fora do lugar: uma análise comparada entre a Sentencia T025 e a ADPF 347/DF-MC. In: VIEIRA, José Ribas; CAMARGO, Margarida Maria Lacombe; SIDDHARTA, Legale. (Org.). Jurisdição constitucional e direito constitucional internacional. Belo Horizonte: Editora Fórum, 2016. p. 203-223. 
VIEIRA, Oscar Vilhena. A batalha dos poderes: da transição democrática ao malestar constitucional. São Paulo: Companhia das Letras, 2018.

VALLE, Vanice Regina Lírio do Valle; SILVA, Cecília de Almeida.

Constitucionalismo cooperativo ou a supremacia do Judiciário? Jurispoiesis (Rio de Janeiro), v. 12, p. 321-348, 2009.

VITORELLI, Edilson. Litígios Estruturais: decisão e implementação de mudanças socialmente relevantes pela via processual. In: ARENHART, Sérgio Cruz; JOBIM, Marco Félix (Org.). Processos Estruturais. Salvador: Juspodivm, 2017. p. 369-422.

VITORELLI, Edilson. O devido processo legal coletivo: representação, participação e efetividade da tutela jurisdicional. 2015. 719 f. Tese (Doutorado) Curso de Direito, Ciências Jurídicas, Universidade Federal do Paraná, Curitiba, 2015.

WILLIAMS, John J.. Community participation. Policy Studies, [s.1.], v. 27, n. 3, p. 197-217, set. 2006.

ZAGREBELSKY, Gustavo. A crucificação e a Democracia. São Paulo: Editora Saraiva, 2011. 